BEFORE THE FLOOD 
This page intentionally left blank 


\title{
BEFORE THE FLOOD
}

\author{
THE ITAIPU DAM \\ AND THE VISIBILITY \\ OF RURAL BRAZIL
}

JACOB BLANC

DUKE UNIVERSITY PRESS

Durham and London 2019 
(C) 2019 Duke University Press

All rights reserved

Printed in the United States of America on acid-free

$$
\text { paper } \infty
$$

Cover designed by Courtney Leigh Baker

Typeset in Minion Pro by Westchester Publishing Services

Library of Congress Cataloging-in-Publication Data

Names: Blanc, Jacob, author.

Title: Before the flood : the Itaipu Dam and the visibility of rural Brazil / Jacob Blanc.

Description: Durham : Duke University Press, 2019. | Includes bibliographical references and index.

Identifiers: LCCN 2019006363 (print)

LCCN 2019016266 (ebook)

ISBN 9781478005322 (ebook)

ISBN 9781478004295 (hardcover : alk. paper)

ISBN 9781478004899 (pbk. : alk. paper)

Subjects: LCsH: Itaipu (Power plant) | Itaipu (Power plant)—

Political aspects. | Dams-Brazil. | Land reform-Brazil.

Classification: LCC TK1442.I85 (ebook) | LCC TK1442.I85

B536 2019 (print) | DDC 333.91/415098162-dc23

LC record available at https://lccn.loc.gov/2019006363

Cover art: Itaipu Dam. Alexandre Marchetti /

Itaipu Binacional

This book received a publication subsidy from Duke

University Press's First Book Fund, a fund established by

Press authors who donate their book royalties to help support innovative work by junior scholars. 
FOR IZZY 
This page intentionally left blank 